\title{
Postpulmonary embolism pericarditis: A case report and review of the literature
}

\author{
FINLAY A MCALISTER MD FRCPC, MOHAMMED AL-JAHLAN MD, BRUCE FISHER MD FRCPC \\ Division of General Internal Medicine, University of Alberta Hospital, Edmonton, Alberta
}

FA MCAlister, M Al-Jahlan, B Fisher. Postpulmonary embolism pericarditis: A case report and review of the literature. Can Respir J 1996;3(1):13-16.

Pericarditis developing as a sequela of pulmonary embolism has been rarely described. A 44-year-old male presented with acute dyspnea and pleuritic pain; V/Q scan showed multiple perfusion defects, and he was treated with heparin. Three days later retrosternal pain was accompanied by a pericardial friction rub. There was a rapid response to systemic corticosteroid therapy; anticoagulation was continued. Steroids were discontinued after four weeks, and anticoagulation (warfarin) was continued. Two months later he presented with clinical features of pulmonary embolus and new perfusion defects on scan. He was treated with heparin and warfarin; three weeks later clinical features of pericarditis recurred, and he was again treated successfully with four weeks' oral prednisone. Three months later pericarditis recurred without signs of pulmonary embolism; computed tomography scan showed thickening of the pericardium. The patient was asymptomatic for five months on indomethacin. A literature search showed 11 cases of pericarditis associated with emboli, all responding promptly to steroids. Continuation of anticoagulation does not appear to increase the risk (or magnitude) of hemorrhagic pericardial effusion.

Key Words: Anticoagulation, Pericarditis, Pulmonary embolism

\section{Péricardite secondaire à une embolie pulmonaire : Étude de cas et revue de la littérature}

RÉSUMÉ : La péricardite en tant que séquelle d'une embolie pulmonaire a été rarement décrite. Un homme de 44 ans s'est présenté avec une dyspnée et une douleur pleurétique aiguës ; la scintigraphie pulmonaire de ventilation-perfusion a révélé de multiples défauts de perfusion ; ce patient a donc été traité avec de l'héparine. Trois jours plus tard, une douleur rétrosternale accompagnée d'un frottement péricardique a répondu favorablement à l'administration de corticoïdes par voie systémique tandis que le traitement anticoagulant s'est poursuivi. Après quatre semaines, on a interrompu le traitement par stéroïdes et maintenu le traitement anticoagulant à la warfarine. Deux mois plus tard, le patient a de nouveau présenté des signes cliniques d'embolie pulmonaire et, la scintigraphie a révélé de nouveaux défauts de perfusion. Il a de nouveau été traité avec de l'héparine et de la warfarine. Trois semaines plus tard, le patient a de nouveau manifesté des signes cliniques de péricardite traités favorablement avec de la prednisone par voie orale pendant 4 semaines. Trois mois plus tard, la péricardite est réapparue, sans signes d'embolie pulmonaire; l'examen tomodensitométrique a révélé un épaississement du péricarde. Le patient a reçu de l'indométhacine et, il est resté asymptomatique pendant 5 mois. Une revue de la littérature a révélé 11 cas de péricardite associée à un embole. Tous les cas avaient rapidement répondu à un traitement par stéroïdes. Le maintien du traitement anticoagulant ne semble pas accroître le risque (ou l'importance) d'épanchement péricardique hémorragique. 
$\mathrm{P}$ ericarditis occurring as a sequelae of myocardial infarction, pericardiotomy or chest trauma is well recognized (1-3); however, pericarditis following pulmonary embolism has only rarely been described (4-7). Recognition of this condition allows appropriate treatment decisions to be made and may spare the patient an extensive diagnostic workup for presumed idiopathic pericarditis. We describe a case of recurrent pericarditis developing in a patient with no obvious cause other than recent pulmonary emboli and review the literature with respect to management of this condition.

\section{CASE PRESENTATION}

A 44-year-old male smoker (20 pack years) presented after sudden onset of dyspnea and pleuritic chest pain. He had been previously healthy with no prior history of thromboembolic disease, collagen vascular disease or trauma, and with

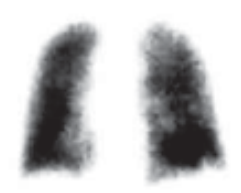

POST VENT

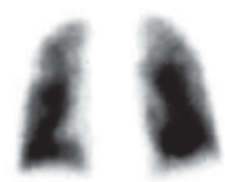

POST PERF

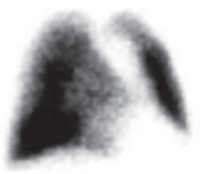

RAO VENT

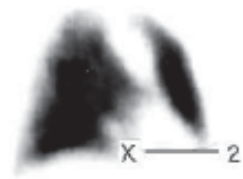

RAO PERF

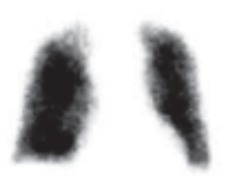

ANT VENT

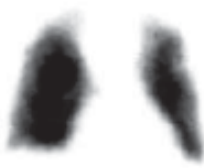

ANT PERF
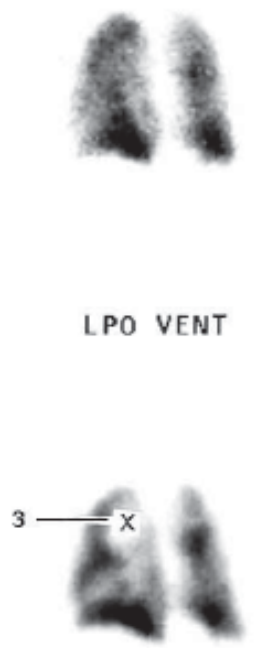

L.PO PERF

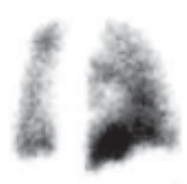

RPO VENT

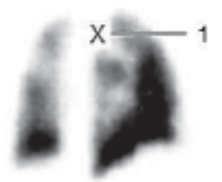

RPO PERF

\section{VQ LUNG SCAN}

\section{UAH EDMONTON}

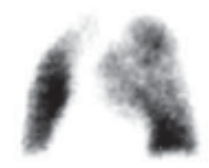

LAO VENT

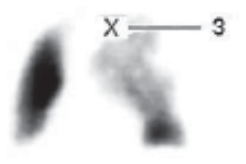

LAO PERF

Figure 1) Initial ventilation perfusion lung scan. Multiple perfusion defects are evident in the posterior segment of the right upper lobe (1), the medial segment of the right middle lobe (2) and the apical-posterior segment of the left upper lobe (3). Given the clinical history (high pretest probability), this scan indicated a high probability for multiple pulmonary emboli. LAO Left anterior oblique; LPO Left posterior oblique; RAO Right anterior oblique; RPO Right posterior oblique 
no prodromal symptoms suggestive of a viral illness. He was afebrile and normotensive, and the chest examination was normal. Examination of the cardiovascular system was unremarkable with normal jugular venous pressure and wave form, normal first and second heart sounds, and no added sounds.

On admission, a complete blood count and erythrocyte sedimentation rate (ESR) were normal. Arterial blood gases demonstrated a $\mathrm{PO}_{2}$ of $59 \mathrm{mmHg}$ and a $\mathrm{PCO}_{2}$ of $39 \mathrm{mmHg}$. A chest radiograph revealed normal cardiac silhouette and lung fields (no evidence of infiltrate or oligemia). A ventilation-perfusion lung scan (V/Q scan) demonstrated one segmental and two subsegmental mismatched perfusion defects; one of the defects was in the region of the right middle lobe (Figure 1). Given the high pretest probability and the fact that a repeat perfusion scan after three days of intravenous heparin therapy demonstrated resolution of all but the segmental defect, it was felt that the scans indicated a high probability of multiple pulmonary emboli. He was treated with oxygen and intravenous heparin to keep his activated partial thromboplastin time (aPTT) in a therapeutic range of 50 to $70 \mathrm{~s}$.

On the third day of hospitalization, he developed a new retrosternal pain which was described as sharp, worsened by movement and swallowing, and improved by leaning forward. He was found to have a loud pericardial friction rub and a low grade fever. The ESR was elevated to $45 \mathrm{~mm} / \mathrm{h}$ and an electrocardiogram demonstrated nonspecific ST-T wave flattening. A transthoracic echocardiogram revealed a small amount of pericardial fluid but normal wall motion and cardiac function. A diagnosis of pericarditis was made and various investigations were done to exclude common etiologies. Serial electrocardiograms and myocardial enzymes were normal; rheumatoid factor and antinuclear antibodies were negative; and blood cultures, serological studies for human immunodeficiency virus and Coxsackievirus, and throat swabs for bacterial culture and viral inclusion bodies did not reveal any evidence for bacterial or viral infections.

Corticosteroid therapy (prednisone $40 \mathrm{mg}$ daily) was initiated and the pericardial rub and pain resolved within a few hours. The intravenous heparin was continued such that the aPTT remained in therapeutic range, and serial clinical examinations, electrocardiograms, chest radiographs and echocardiograms did not reveal any increase in the size of the pericardial effusion. The patient was given warfarin without incident and discharged home (with prothrombin time maintained at an international normalized ratio [INR] of 2 to 3 ) with a four-week tapering course of prednisone. After discontinuation of the prednisone, the patient initially remained well without recurrence of symptoms or the pericardial rub.

Two months after discharge, following a $28 \mathrm{~h}$ car journey, the patient again presented with signs and symptoms consistent with a pulmonary embolism. His anticoagulation was found to be subtherapeutic (prothrombin time INR 1.6). A repeat V/Q scan demonstrated new lesions compatible with a high probability for recurrent pulmonary embolism. He was treated with heparin and warfarin, then discharged home with a therapeutic prothrombin time INR of 2.5 to 3.5. Antithrombin III, protein $\mathrm{C}$ and protein $\mathrm{S}$ assays were normal, and anticardiolipin antibody testing was negative. Although there had been no evidence of pericarditis during this admission, he presented three weeks later after the acute onset of signs and symptoms consistent with pericarditis. A pulmonary angiogram at this point was negative and a transthoracic echocardiogram did not reveal any pericardial effusion. He was continued on warfarin, and prednisone was re-initiated at a dose of $40 \mathrm{mg}$ daily. By the next morning, his symptoms had resolved completely and he was discharged home to complete another four-week course of corticosteroids.

Although he initially felt well and was asymptomatic after discontinuation of the corticosteroids, the patient presented three months later with another episode of acute pericarditis. A repeat V/Q scan demonstrated good perfusion to all segments of both lungs and was felt to represent a low probability for pulmonary emboli. Echocardiogram revealed a small pericardial effusion, which was not significantly different from the effusions documented in prior echocardiograms. An augmented computed tomography scan of the chest revealed a markedly thickened pericardium but was otherwise unremarkable. Complete blood cell count and complement levels were normal and Mantoux test was negative; assays for antidouble-stranded DNA and antinuclear antibodies were negative. In the absence of other symptoms or signs suggesting an underlying etiology, the patient was diagnosed with recurrent postpulmonary embolism pericarditis. He was placed on therapy with indomethacin $25 \mathrm{mg}$ tid and remained asymptomatic with no recurrence of pericarditis over the following five months.

\section{DISCUSSION}

Our patient initially developed pericarditis three days after a pulmonary embolism and had recurrence of pericarditis three weeks and three months after a second episode of pulmonary embolism. In the absence of evidence for any other etiology, we assume the episodes of pericarditis were secondary to the pulmonary emboli. Postpulmonary embolism pericarditis has been reported in 11 patients in the Englishlanguage literature (4-7). The clinical manifestations are varied but include fever, pericarditis (with or without effusion), leukocytosis and an elevated ESR. The onset of the syndrome has ranged from three days to two months after the pulmonary embolism.

The pathogenesis of postpulmonary embolism pericarditis is unknown, although anatomical vicinity and hypersensitivity are hypothesized to play a role. McGinn and White (8) described a pericardial rub developing in patients with large pulmonary emboli and resultant cor pulmonale, and theorized that there was friction between the dilated pulmonary artery or right ventricle and the parietal pericardium. In our patient, the right middle lobe embolism could have caused inflammation of the adjacent pleura and consequently the parietal pericardium. Other authors $(4,6,7)$ have hypothesized that tissue infarction secondary to pulmonary embolism may result in the release of antigens with a subsequent hypersensi- 
tivity reaction leading to pericardial inflammation. However, in our patient, there was no evidence of pulmonary infarction after either of his emboli.

All 11 cases in the literature were treated with high dose systemic corticosteroids and had prompt resolution of their symptoms. Interestingly, none of the patients suffered adverse sequelae from the continuation of anticoagulants after development of pericarditis, although one patient did die from recurrent pulmonary embolism 25 days later. Thus, it seems prudent to continue with therapeutic levels of antico-

\section{REFERENCES}

1. Dressler W. Post-myocardial infarction syndrome: preliminary report of a complication resembling idiopathic, recurrent, benign pericarditis. JAMA 1956;160:1379-83.

2. Engle MA, Ito T. The postpericardiotomy syndrome. Am J Cardiol 1961;7:73-82.

3. Tabatznick B, Isaac JP. Postpericardiotomy syndrome following traumatic hemopericardium. Am J Cardiol 1961;7:83-96.

4. Sklaroff HJ. The post-pulmonary infarction syndrome. Am Heart J 1979;98:772-6.

5. Sklaroff HJ. Postpulmonary infarction syndrome: case report. agulation and to initiate systemic corticosteroids promptly in patients who develop pericarditis after a pulmonary embolism. In patients with recurrent pericarditis, long term therapy with a nonsteroidal anti-inflammatory agent seems to be effective in preventing relapses.

ACKNOWLEDGEMENTS: The authors thank Dr M Hoskinson and $\mathrm{Dr} C$ Maguire for their expert assistance in interpreting the V/Q scans.

Mt Sinai J Med 1983;50:343-7.

6. Jerjes-Sanchez C, Ibarra-Perez C, Ramirez-Rivera A, Padua-Gabriel A, Gonzalez-Carmona VM. Dressler-like syndrome after pulmonary embolism and infarction. Chest 1987;92:115-7

7. Garty I, Mader R, Schonfeld S. Post pulmonary embolism pericarditis: A rare entity diagnosed by combined lung scanning and chest radiograph study. Clin Nucl Med 1994;19:519-21.

8. McGinn S, White PD. Acute cor pulmonale resulting from pulmonary embolism: its clinical recognition. JAMA 1935; 104:1473-80. 


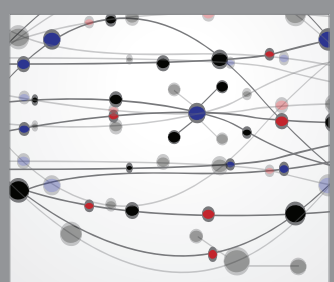

The Scientific World Journal
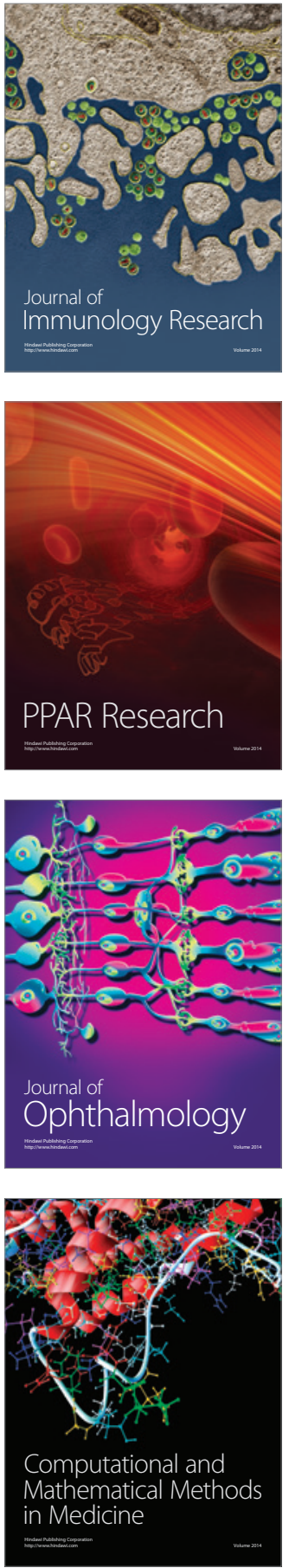

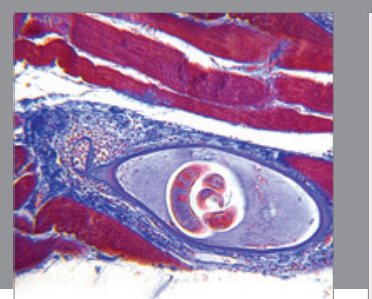

Gastroenterology Research and Practice

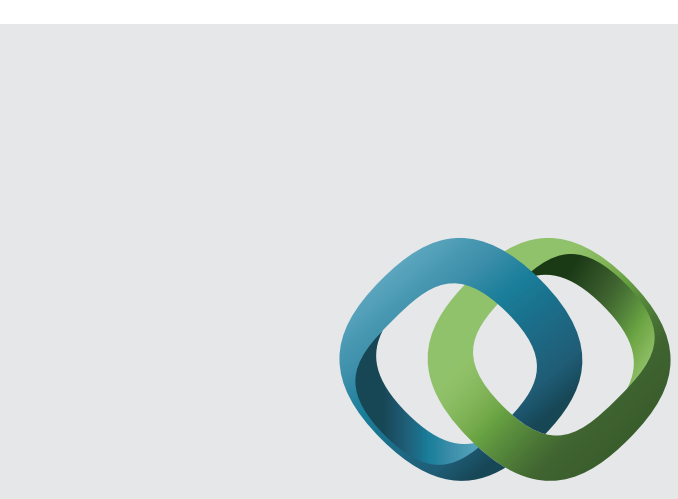

\section{Hindawi}

Submit your manuscripts at

http://www.hindawi.com
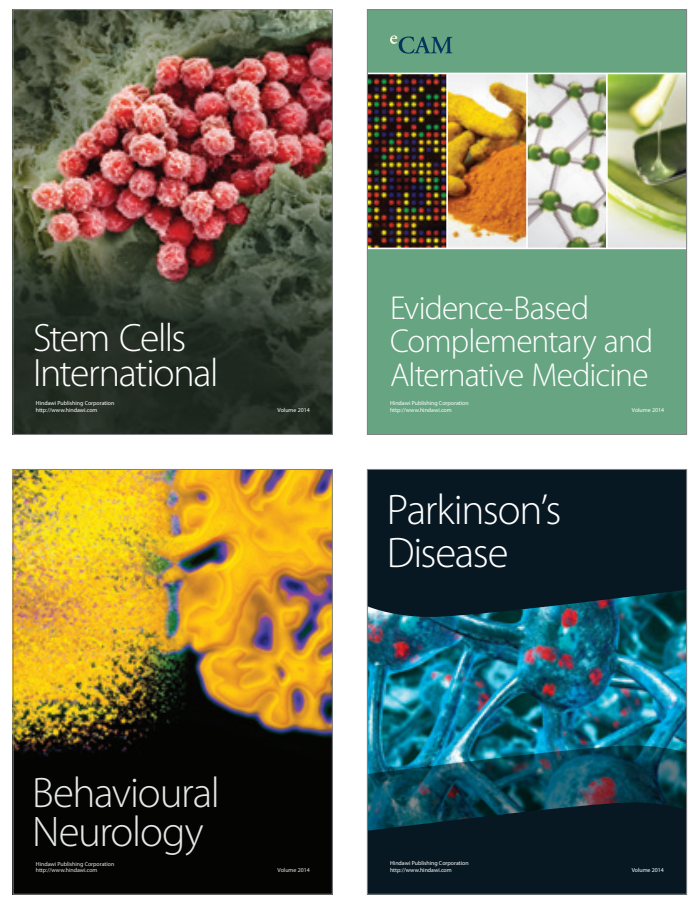
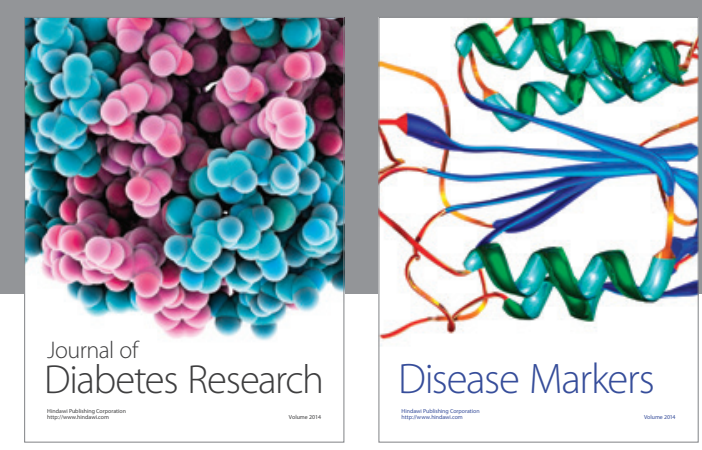

Disease Markers
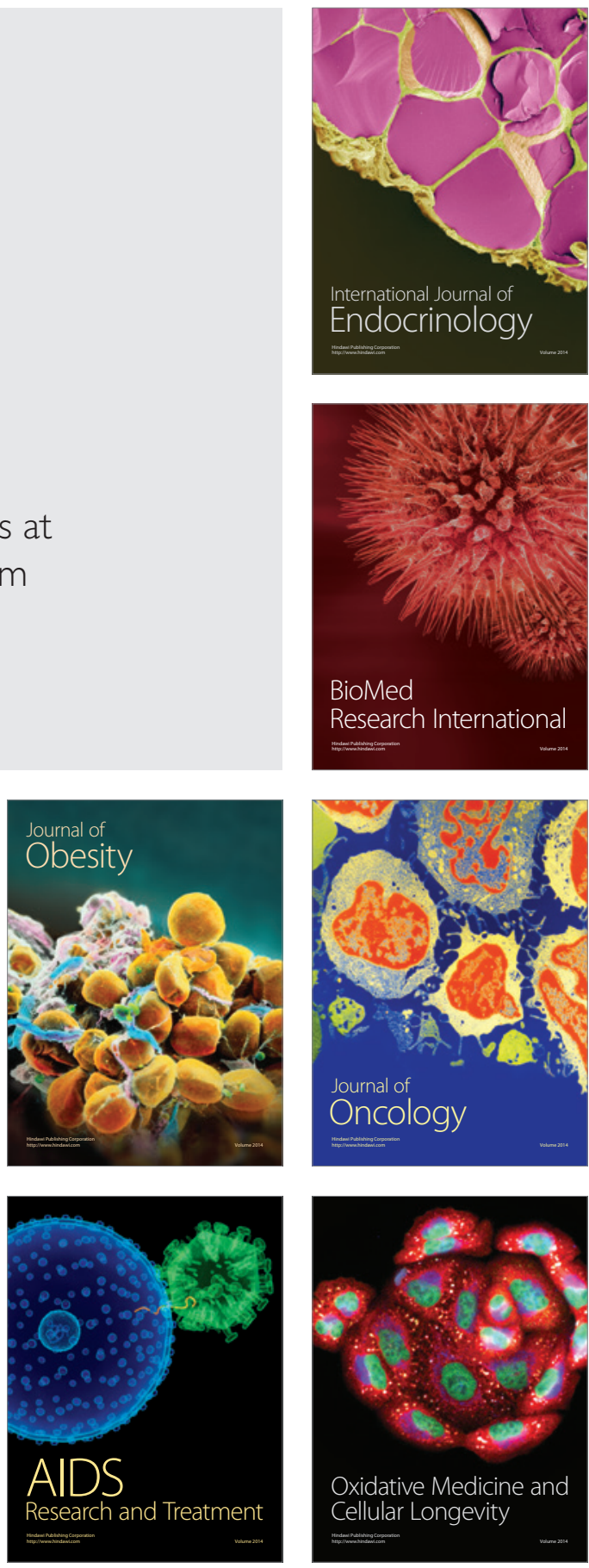